\title{
Functional Heartburn and Non-Erosive Reflux Disease
}

\author{
Vincenzo Savarino Edoardo Savarino Andrea Parodi Pietro Dulbecco \\ Dipartimento di Medicina Interna e Specialità Mediche, Università degli Studi di Genova, Genova, Italy
}

\section{Key Words}

Functional heartburn $\cdot$ Non-erosive reflux disease $\cdot$

Gastroesophageal reflux disease $\cdot$ Proton pump inhibitors index. Their response to PPIs is very disappointing. Therefore, there is an increasing consensus on the fact that they do not have GERD and should be treated with drugs other than PPIs.

Copyright $\odot 2007$ S. Karger AG, Basel

\begin{abstract}
Gastroesophageal reflux disease (GERD) is a common disorder in Western countries. For many years our attention has been focused on patients with erosive esophagitis, but in recent times we have realized that endoscopy-negative reflux disease is the most common presentation of this illness, affecting up to $70 \%$ of these individuals. Patients with the non-erosive form (NERD) are a heterogeneous group including various subpopulations with different mechanisms for their main symptom of heartburn: reflux of acidic and nonacidic gastric contents, mucosal hypersensitivity, intraesophageal distension by gas, intraduodenal infusion of fat, muscle contractions and psychological abnormalities. As to esophageal acid exposure, patients with NERD can be subdivided into those with abnormal and normal $\mathrm{pH}$ testing. The latter group includes patients with a positive correlation between symptoms and reflux events, in whom heartburn can be controlled by proton pump inhibitor (PPI) therapy. According to the recent Rome III criteria, they are still in the realm of GERD. An additional group is called functional heartburn, because this typical symptom is associated neither with an abnormal pH test nor with a positive symptom
\end{abstract}

(C) 2007 S. Karger AG, Basel

0257-2753/07/0253-0172\$23.50/0

ax +4161306 1234

E-Mail karger@karger.ch

www.karger.com
Accessible online at: www.karger.com/ddi
Typical symptoms of gastroesophageal reflux disease (GERD), such as heartburn and regurgitation, occur weekly in $20 \%$ of the adult population of Western countries [1]. For many years our understanding of GERD was largely limited to patients with erosive esophagitis. More recently, however, we have realized that the majority of GERD patients do not have any endoscopically visible lesion in the distal part of their esophagus. They represent up to $70 \%$ of all patients with reflux symptoms and are defined as affected by non-erosive reflux disease (NERD). Although they do not present anatomical breaks in their esophageal mucosa, most NERD patients demonstrate a chronic pattern of symptoms with periods of exacerbation and remission, a behavior which is quite similar to that of patients with the erosive form. Heartburn is the most classic symptom of NERD and therefore it can be perceived by patients with and without mucosal injury. This symptom can originate from various stimuli inside and outside the esophagus [2]. An abnormal esophageal acid exposure is certainly able to induce heartburn, but 
the same symptom can be produced by a physiological intraesophageal $\mathrm{pH}$ [3]. It has also been demonstrated that the infusion of fat into the duodenum enhances the perception of intraesophageal acid and may be a major modulator of postprandial reflux symptoms [4]. Chest pain and heartburn have been also provoked in normal subjects during esophageal balloon distension either in the proximal or the distal portion of the esophagus [5]. Pehlivanov et al. [6] suggested that longitudinal muscle contractions of the esophagus observed by high-frequency intraluminal ultrasound are the motor equivalent of heartburn sensation. Finally, heartburn can also be the result of an increased perception of normal peripheral stimuli at the central level [7]. In other words, heartburn can be the common final response to a variety of intraand extraesophageal stimuli.

In NERD patients lacking esophageal mucosal damage, the mechanism leading to heartburn can be represented by the presence of some histological abnormalities favoring the diffusion of hydrogen ions through the esophageal epithelium and the consequent stimulation of sensory neurons. In both animal models and humans, dilation of intercellular spaces has been noted in acid-exposed tissues by means of transmission electron microscopy $[8,9]$. More recently, it has been shown that dilated intercellular spaces can be observed in $80 \%$ of NERD patients even using optical microscopy, which is more practical than electron microscopy in clinical routine [10]. However, it is currently accepted that an excess of intraesophageal acid is not present in many patients with NERD. It has been shown that between 33 and 50\% of these patients presenting with heartburn do not have any evidence of pathological acid reflux by 24 -hour esophageal $\mathrm{pH}$ testing $[2,11]$. We have already mentioned that factors other than acid can be responsible for heartburn in this large subgroup of NERD patients. Therefore, it is clear that NERD is an umbrella concept underlying heterogeneous subgroups of patients with different mechanisms responsible for their symptoms. This also explains why the therapeutic response to antisecretory drugs is overall lower in patients with NERD compared with those achievable in erosive esophagitis [12].

NERD patients with normal esophageal acid exposure met the Rome II diagnostic criteria set for functional heartburn. The recently published Rome III criteria, however, have emphasized that a further subclassification of these patients is needed [13]. Those individuals showing a close temporal relationship between symptoms and acid reflux events, despite having an esophageal acid exposure within the physiological range, can be con- sidered as GERD patients. They demonstrate a positive response to antisecretory drugs, particularly when high doses of proton pump inhibitors (PPIs) are adopted [14]. So, the acid-sensitive esophagus is now excluded from the group of functional esophageal disorders and considered within the realm of GERD.

On the contrary, retrosternal burning in the absence of esophagitis at endoscopy, with negative $\mathrm{pH}$ test and non-response to a therapeutic trial with PPIs meets the essential criteria for the diagnosis of functional heartburn. In these patients the role of acid in inducing heartburn is excluded and the relevance of weakly acid or alkaline reflux remains unproven. However, there is no doubt that functional heartburn is something other than GERD. Disturbed visceral perception or altered central symptom processing seem to be the major factors involved in pathogenesis. Psychological factors may also be important in heartburn reporting and, thus, this symptom unrelated to GERD may respond to low-dose tricyclic antidepressants.

As these patients represent the group mostly responsible for PPI failure, multichannel intraluminal impedance (MII) plus traditional $\mathrm{pH}$-metry can be the best tool to identify them. A recent study [15] using this novel technique on a large group of patients unresponsive to PPIs has shown that they can be categorized into three distinct subgroups: $11 \%$ had symptoms related to acid reflux, $37 \%$ had symptoms related to non-acid reflux, and $58 \%$ had symptoms related neither to acid reflux nor to non-acid reflux. This means that most patients unresponsive to PPIs have symptoms which are not related to any kind of reflux, and those with refractory heartburn can be better classified on the basis of MII + pH-metry as affected by functional heartburn which is likely to generate many of the PPI failures in patients with NERD.

In conclusion, NERD is an umbrella concept which underlies heterogeneous subgroups of patients without endoscopically visible lesions of esophageal mucosa. They differ from each other because of distinct pathophysiological features and variable response to treatment with the powerful antisecretory drugs which are today available for therapy of GERD. Patients with functional heartburn are part of the above large and complex population of NERD and are characterized by normal esophageal acid exposure and negative symptom index. These patients cannot be considered as affected by GERD and should be treated with drugs other than acid-lowering agents, because they are responsible for the most part of PPI failures in patients with NERD. 


\section{References}

1 Locke GR, Talley NJ, Fett SL, et al: Prevalence and clinical spectrum of gastroesophageal reflux: a population-based study in Olmsted County, Minnesota. Gastroenterology 1997;112:1448-1456.

$>2$ Fass R, Fennerty B, Vakil N: Nonerosive reflux disease - current concepts and dilemmas. Am J Gastroenterol 2001;96:303-314.

$>3$ Trimble KC, Douglas S, Pryde A, et al: Clinical characteristics and natural history of symptomatic but not excess gastroesophageal reflux. Dig Dis Sci 1995;40:1098-1104.

$\checkmark 4$ Lembo A, Naliboff B, Munataka J, et al: Intraduodenal fat alters perceptual and autonomic responses to acid perfusion of the esophagus in GERD patients. Gastroenterology 1998;114:G0819.

5 Fass R, Naliboff B, Higa L, et al: Differential effect of long-term acid exposure on mechanosensitivity and chemosensitivity in humans. Gastroenterology 1998;115:13631373.
6 Pehlivanov ND, Liu J, Mittal R: Sustained esophageal contraction: a motor correlate of heartburn symptom. Gastroenterology 1999; 116:G4613.

77 Fass R, Tougas G: Functional heartburn: the stimulus, the pain, and the brain. Gut 2002; 51:885-892.

8 Ferreira KG, Hill BS: The effect of low external $\mathrm{pH}$ on properties of the paracellular pathway and junctional structure in frog skin. J Physiol 1982;332:59.

$\checkmark 9$ Caviglia R, Ribolsi M, Maggiano N, et al: Dilated intercellular spaces of esophageal epithelium in nonerosive reflux disease patients with physiological esophageal acid exposure. Am J Gastroenterol 2005;100:543548.

10 Zentilin P, Savarino V, Mastracci L, et al: Reassessment of the diagnostic value of histology in patients with GERD, using multiple biopsy sites and an appropriate control group. Am J Gastroenterol 2005;100:22992306.
11 Watson RGP, Tham TCK, Johnston BT, et al: Double blind cross-over placebo controlled study of omeprazole in the treatment of patients with reflux symptoms and physiological levels of acid reflux, the 'sensitive esophagus'. Gut 1997;40:587-590.

12 Fass R: Distinct phenotypic presentations of gastroesophageal reflux disease: a new view of the natural history. Dig Dis 2004;22:100107.

13 Galmiche JP, Clouse RE, Bàlint A, et al: Functional esophageal disorders. Gastroenterology 2006;130:1459-1465.

14 Numans ME, Lau J, de Wit NJ, et al: Shortterm treatment with proton-pump inhibitors as a test for gastroesophageal reflux disease: a meta-analysis of diagnostic test characteristics. Ann Intern Med 2004;140: 518-527.

15 Mainie I, Tutuian R, Shay S, et al: Acid and non-acid reflux in patients with persistent symptoms despite acid suppressive therapy. A multicentre study using combined ambulatory impedance $\mathrm{pH}$ monitoring. Gut 2006; 55:1398-1402. 